\title{
DEPOCEN
}

Working Paper Series No. 2013/7

\section{A Stochastic Dynamic Model of Trade and Growth: Convergence and Diversification}

\author{
Partha Chatterjee* \\ Malik Shukayev ${ }^{* *}$
}

*FMS, University of Delhi, Delhi 110007; partha@fms.edu

**Bank of Canada; mshukayev@bankofcanada.ca

The DEPOCEN WORKING PAPER SERIES disseminates research findings and promotes scholar exchanges in all branches of economic studies, with a special emphasis on Vietnam. The views and interpretations expressed in the paper are those of the author(s) and do not necessarily represent the views and policies of the DEPOCEN or its Management Board. The DEPOCEN does not guarantee the accuracy of findings, interpretations, and data associated with the paper, and accepts no responsibility whatsoever for any consequences of their use. The author(s) remains the copyright owner.

DEPOCEN WORKING PAPERS are available online at http://www.depocenwp.org 


\title{
A Stochastic Dynamic Model of Trade and Growth: Convergence and Diversification
}

\author{
Partha Chatterjee \\ FMS, University of Delhi, Delhi 110007 \\ partha@fms.edu
}

\author{
Malik Shukayev \\ Bank of Canada \\ mshukayev@bankofcanada.ca
}

\begin{abstract}
There is a growing literature that studies the properties of models that combine international trade and neoclassical growth theory, but mostly in a deterministic setting. In this paper we introduce uncertainty in a dynamic Heckscher-Ohlin model and characterize the equilibrium of a small open economy in such an environment. We show that, when trade is balanced period-by-period, the per capita output and consumption of a small open economy converge to an invariant distribution that is independent of the initial wealth. Further, at the invariant distribution, there are periods in which the small economy diversifies. Numerical simulations show that the speed of convergence increases with the size of the shocks. In the limit, when there is no uncertainty, there is no convergence and countries may specialize permanently. The paper highlights the role of market incompleteness, as a result of the period-by-period trade balance, in this setup. Through an analytical example we also illustrate the importance of country specific risk in delivering our results.

Keywords: Economic Growth; International Trade; Heckscher-Ohlin; Convergence; Stochastic Growth Theory; Diversification; Incomplete markets; Risk.

JEL Codes: F1, F4, O4, E2.
\end{abstract}




\section{Introduction}

The theory of neoclassical growth has traditionally been developed in the closed economy environment. Though, there has been some early attempts to integrate international trade and neoclassical growth (see for example, Bardhan 1965, and Oniki and Uzawa 1965), it is only more recently that there has been a surge of interest in such dynamic trade models. However, most of the papers in this research area have restricted attention to the dynamics of an open economy in an environment without uncertainty. In this paper we analyze a stochastic dynamic model which integrates neoclassical growth and trade and characterize the equilibrium of a small economy in such an environment. We use this model to address two central issues-convergence of income, a recurring question in the growth literature and diversification of trade, a common concern in the trade literature. In doing so, we illustrate the interplay of trade, diversification of production and uncertainty in an incomplete markets setting.

Specifically we study the properties of a dynamic Heckscher-Ohlin model with uncertainty. Just as in the one-sector neoclassical growth model, we obtain income convergence across countries. We show that, when trade is balanced period-byperiod, a standard assumption in deterministic Heckscher-Ohlin models, the per capita output and consumption of a small open economy converge to an invariant distribution that is independent of the initial wealth. Further, we find that when income of an economy is within the invariant distribution, there will surely be some periods in which the small economy diversifies.

The closed economy neoclassical growth theory, which has been a standard vehicle to answer the question of income convergence across countries, predicts that, as long as countries have the same preferences, technologies, and population dynamics, they will converge to the same level of per capita income from any (positive) initial wealth. The closed economy version of the neoclassical growth model has been extended to incorporate uncertainty by Brock and Mirman (1972), who show that countries will converge to the same invariant distribution of income irrespective of their positive initial wealth.

Bardhan (1965), and Oniki and Uzawa (1965), who studies dynamic HeckscherOhlin models with fixed savings rates, were the first to study integrated models of growth and trade. More recently Chen (1992), Ventura (1997), Deardorff (2001), Cunat and Maffezzoli (2004b) and Bajona and Kehoe (2006b) have used twocountry models while Atkeson and Kehoe (2000) have used a small open economy 
model to study the dynamics of an open economy $1 \frac{1}{1}$ These recent papers have used deterministic dynamic Heckscher-Ohlin models - that is models with two or more tradable commodities produced with neoclassical production functions that differ in capital intensities - and have found that it is possible that income levels across countries do not converge (see Bajona and Kehoe 2006b for more details about conditions under which countries do not converge in a two-country model). Although the models vary in details, trade-induced factor-price equalization, which leads to existence of multiple steady states and specialization, is a common feature across all of them.

In these models factor-price equalization ensures that the rate of return on capital is same in all countries that have their aggregate capital-labor ratios within the diversification cone. As a result, if the world economy, which is within the cone of diversification, is in a steady state, then all countries with different aggregate capital-labor ratios within the diversification cone must be in a steady state. Outside the diversification cone the rate of return depends on the country's own capital, and the diminishing returns to capital ensure that countries that start with a low capital-labor ratio outside the diversification cone, will grow until they reach the lower boundary of the diversification cone. Such countries will never enter the interior of the diversification cone and will permanently specialize in the production of tradable goods that are less capital intensive. The case for the countries which start with a capital-labor ratio above the diversification cone is symmetric. Thus, the initial conditions will determine the fate of a country in the long run.

What difference does uncertainty make? In our model, with country specific shock and market incompleteness initial conditions don't matter. When the country's capital-labor ratio is outside the cone of diversification, the diminishing returns to its own capital pushes it towards the boundary of diversification cone. Inside the cone of diversification the rate of return is independent of the small country's capital, but the real rate of return still depends on the country's shocks. Now, since different countries face different shocks there would be mutual gains through risk-sharing if countries could borrow from and lend to each other. Borrowing constraint as a result of period-by-period trade balance prevents that ${ }^{2}$ Un-

\footnotetext{
${ }^{1}$ We focus on the integration of neoclassical growth and trade. Some papers, for example Fisher (1995) and Bond et al. (2003), study dynamic Heckscher-Ohlin models with endogenous growth. There is a strand of the literature that studies properties of Heckscher-Ohlin models with overlapping generations. For differences between those models and models with infinitely lived agents refer to Bajona and Kehoe (2006a).

${ }^{2}$ We assume period-by-period balanced trade constraint, which is effectively a zero-borrowing constraint, in order to be consistent with deterministic dynamic Heckscher-Ohlin models. As
} 
der these circumstances, with i.i.d. income shocks, the representative household in a small open economy self-insures by accumulating more capital when current income is high and de-accumulating capital when current income is low. Once the country reaches the diversification cone, a long sequence of negative (positive) shocks will push capital holdings of the representative household beyond the lower (upper) boundary of the diversification cone, where further declines (increases) in capital are resisted by changes in the returns to capital. As a result of these effects all small economies converge to the same invariant distribution of capital with its support including the entire diversification cone. Thus, the long run average income of the small economies will be the same and, further, those economies will diversify production at least in some periods.

We also simulate our model to determine how the speed of convergence depends on the size of the shocks that the economy faces. We find that the bigger the shocks are, the faster is convergence. In the limit, when uncertainty vanishes, convergence disappears. This suggests that, if uncertainty is small, initial conditions play an important role in the development of a country: it takes a long time for initially poor countries to catch up with richer countries. The simulations, thus, provide a sense of continuity between the deterministic and the stochastic models. The simulations also illustrate the difference in the shape of the policy function between the deterministic and the stochastic models. Simulations are also useful to get a sense of what happens when the stochastic process is Markovian instead of i.i.d. Our theoretical results in this paper are proved using an i.i.d. process, but we find, in simulations, that even economies that face persistent shocks exhibit similar properties of convergence and diversification. Thus, it is likely that the results in this paper will carry over to an economy that faces persistent shocks.

In order to show the importance of the country-specific shocks we construct an example in which all small economies face the same world-wide productivity shock. In this example, we show analytically, that the small open economies, starting from different initial conditions never converge. This example makes it clear that it is not just the uncertainty that matters.

Our paper closely relate to the papers studying dynamic trade models mentioned earlier. There is another paper which requires mention. Datta (1999)also analyzes the income dynamics under uncertainty in a multi-sector small open economy. Datta considers a general environment with production sets and ex-

Aiyagari (1994) has shown, self-insurance motive for savings is present whenever the borrowing constraint is tighter than the "natural" (i.e. the long-run solvency) constraint. Given that result, we think that our results can be extended to environments in which limited cross-country borrowing is allowed. We however do not pursue that line in this paper. 
ploits its equivalence to the one-sector stochastic growth model to prove the convergence of income process. Datta's environment, however, does not allow for nontradable goods and for primary fixed factors, like labor. Further, she does not study, nor it is easy to extend her model to study, the dynamic interaction between capital accumulation and trade patterns. In contrast, we focus our attention on a neoclassical model with fixed factors and with nontradable goods, standard in growth and trade literature. This enables us to study patterns of growth, trade and specialization and relate our results to the existing literature.

Our paper, as explained earlier, also relates to the literature on income fluctuations problem, which studies savings decisions under uncertainty and market incompleteness. Clarida (1987), Aiyagari (1994), and Chamberlain and Wilson (2000) are just a few examples of papers that fall into this category.

This paper is organized as follows. In section 2, we describe our model's environment. In section 3, we report the equilibrium results for the model, including those on convergence and diversification. In section 4 , we simulate the model and discuss the speed of convergence. In section 5, we present the analytical example with the world-wide shocks. Finally, we conclude in section 6. All the proofs are collected in the appendix.

\section{The Environment}

The economic environment consists of two economies: a small economy and the rest-of-the-world economy (which can be thought of as a continuum of small economies). The population is fixed in both countries. We assume that the population size in the small country is of measure zero relative to the rest of the world. Motivated by this assumption, and for brevity, we refer to the rest-of-the world economy as simply the world economy.

Our focus is the small open economy that has no effect on world prices of tradable goods 3 . We assume the small economy and the world economy have identical preferences and technologies (except for stochastic productivity factors in the final goods sector). In each economy there are two intermediate goods, $a$ (agriculture) and $m$ (manufacturing), and one final good, $Y$. The intermediate goods are produced using capital and labor in each intermediate-good sector.

\footnotetext{
${ }^{3}$ Others who have studied dynamic Heckscher-Ohlin models with small economy assumption include Findlay (1970), Mussa (1978), Smith (1984), and Atkeson and Kehoe (2000). Stiglitz (1970) also studies the dynamics of a small open economy (though his steady state results are for a two-country model).
} 
Technology for producing good $a$ is less capital intensive than the technology for producing $m$. The intermediate goods are traded between the economies. The final good is produced by combining the two intermediate goods, and can either be invested or consumed domestically, but cannot be traded across economies 4 Capital and labor are also immobile across borders.

\subsection{Preferences}

The agents in both the economies are assumed to have identical preferences. Representative agents in each economy supply labor inelastically and derive utility from consumption.

\section{Assumption 1}

The utility function, $u: \mathcal{R}_{+} \rightarrow \mathcal{R}_{+}$, has the following properties:

1. $u$ is continuous on $\mathcal{R}_{+}$, bounded below, and (without loss of generality) $u(0)=0$.

2. $u$ is twice continuously differentiable and strictly concave: i.e., $u^{\prime}(c)>0$, $u^{\prime \prime}(c)<0 \quad \forall c \in \mathcal{R}_{++}$.

3. $\lim _{c \rightarrow 0} u^{\prime}(c)=\infty$.

\subsection{Production}

Each economy has access to three technologies: two intermediate-good technologies, $a$ and $m$, and one final-good technology, $Y$. All the production functions are assumed to be standard neoclassical production functions: homogeneous of degree one in all inputs, twice continuously differentiable, and with positive and diminishing marginal products of each input.

The final good is produced by combining intermediate goods $a$ and $m$ :

$$
Y=z H(a, m)
$$

where $z$ is the productivity factor which is potentially stochastic.

\footnotetext{
${ }^{4}$ Alternatively, one can model the economy with two tradable final goods, consumption and investment, with investment good produced using a more capital-intensive technology than the consumption good. Our results will hold in the alternative model as well.
} 
$H(a, m)$ satisfies Assumption $25^{5}$
Assumption 2
$H(a, m)$ exhibits constant returns to scale, and for all $a \geq 0$ and $m \geq 0$,

1. $H(0, m)=H(a, 0)=0$.

2. $H_{1}(a, m)>0, H_{2}(a, m)>0, H_{11}(a, m)<0$ and $H_{22}(a, m)<0$.

There are two distinct production functions, which combine capital and labor to produce intermediate goods. The technology for producing intermediate good $a$ is given by,

$$
a=F\left(K_{a}, L_{a}\right),
$$

where $K_{a}$ and $L_{a}$ are capital and labor employed in sector $a$.

The technology for producing intermediate good $m$ is given by,

$$
m=G\left(K_{m}, L_{m}\right)
$$

where $K_{m}$ and $L_{m}$ are capital and labor employed in sector $m$.

Assumptions on both production functions $F$ and $G$ are similar to that on $H$. In addition, the intermediate technologies satisfy the following boundary conditions.

Assumption 3

Boundary conditions for intermediate technologies:

1. For all $L>0, \lim _{K \rightarrow 0} F_{1}(K, L)=\lim _{K \rightarrow 0} G_{1}(K, L)=\infty$.

2. For all $L>0, \lim _{K \rightarrow \infty} F_{1}(K, L)=\lim _{K \rightarrow \infty} G_{1}(K, L)=0$.

We also assume, as is standard in Heckscher-Ohlin models, that the good $m$ technology is more capital intensive than the good $a$ technology for all relevant factor-price ratios (i.e., there are no factor intensity reversals). This is stated more formally in Assumption 4.

Assumption 4

For all $K>0$ and $L>0 \quad \frac{F_{2}(K, L)}{F_{1}(K, L)}>\frac{G_{2}(K, L)}{G_{1}(K, L)}$.

\footnotetext{
${ }^{5}$ We use $H_{1}$ to represent the partial derivative of $H$ with respect to its first argument. We do the same for all other first and second derivatives.
} 


\subsection{International trade}

The final good, capital, and labor are not tradable across countries. The only commodities that can be traded between the economies are the two intermediate goods. Thus, the quantities of intermediate goods utilized in a small economy for the production of final goods can differ from the quantities produced in the small economy. We assume, as is standard in deterministic dynamic Heckscher-Ohlin models, that trade is balanced in each period for each economy.

Assumption 5

In all periods $t$,

$$
p_{a t}\left(a_{t}^{i, d}-a_{t}^{i}\right)+p_{m t}\left(m_{t}^{i, d}-m_{t}^{i}\right)=0,
$$

where the variables with superscript $d$ are quantities demanded in country $i$, the variables without superscript $d$ are quantities produced in country $i$, and $p_{a t}, p_{m t}$ are the world prices of intermediate goods. This assumption has no implication on the equilibrium outcomes in deterministic Heckscher-Ohlin models when each economy produces both intermediate goods. In that case, balanced trade is an equilibrium outcome. With country-specific productivity shocks, however, the period-by-period balanced trade constraint is binding and precludes risk-sharing opportunities through borrowing and lending. As we will see later, this constraint plays an important role in determining the equilibrium outcomes. The absence of borrowing or lending due to balanced trade constraint is also reflected in the budget constraint of a representative household (equation 3.1 below).

\subsection{Uncertainty}

We introduce uncertainty as productivity shocks in the production of final goods. Trefler (1993) studied a Heckscher-Ohlin model that included factor-augmenting international productivity differences (though the productivity factors were not stochastic). Cunat and Maffezzoli (2004a) included stochastic factor productivity terms which were different across countries 6 . We assume that productivity across countries is normalized to have the same expected value (the results would be unchanged, except for a normalization of the factor prices, if that was not the case). Since the shock is in the non-traded final good sector, it does not change the relative productivities in the traded sectors and is in effect an income shock in

\footnotetext{
${ }^{6}$ They simulate a specific model with complete markets and assume FPE holds. The focus is on the transmission of shocks in international business cycle.
} 
that country 7 Our results, however, also extend to a more general setting where productivity shocks are both country and sector specific, affecting the production functions of each of the intermediate sector 8 .

In this paper, except in section 5, we assume that the world economy faces no uncertainty. Further, productivity factors in the world economy, $z_{t}^{w}$, are normalized to be equal to one for all $t$. The small economy, however, faces uncertainty: $z_{t}^{s}$ is stochastic. The following are the assumptions about the distribution of $z_{t}^{s}$ : Assumption 6

1. $z_{t}^{s}$ is an independently and identically distributed (i.i.d.) random variable drawn from its time-invariant distribution.

2. The support of $z_{t}^{s}$ is $Z=[\underline{z}, \bar{z}]$, where $0<\underline{z} \leq \bar{z}<\infty$.

3. $E\left[z^{s}\right]=z^{w}=1$.

The last part of the Assumption 6 states that the expected productivity of the final good sector in the small economy is equal to the productivity of the world economy's final good sector, which is assumed to be non-stochastic and normalized to be one.

Let $\eta$ be the probability measure for the distribution of $z$, defined on the Borel subsets of $Z$. The assumption that $Z$ has full supports implies that $\eta(A)>0$ for any non-degenerate interval, $A$, in the $Z$ space.

At this point, it is useful to state the timing of various events and decision processes in the economy. At the beginning of every period the uncertainty about current productivity level is resolved. The consumers, final-good producers, and intermediate-goods producers all take their decisions after that. The consumers choose how much to consume and save. The savings decision determines the next period's capital. The intermediate-goods producers decide how to allocate the capital and labor available in the economy between the two sectors. Also, the final-good producers decide the amount of each intermediate good to demand, which in turn determines the quantity of exports and imports of each intermediate good. Note that the aggregate capital in the economy is decided before the uncertainty for the period is resolved (it is decided a period earlier), but the allocation of

\footnotetext{
${ }^{7}$ In fact, our results also hold with purely additive (country-specific) endowment shocks, which suggests that cross-country productivity differences are not essential for convergence and diversification.

${ }^{8} \mathrm{~A}$ version of the paper with such shocks is published as a Bank of Canada working paper 2006-23 available at http://www.bankofcanada.ca/wp-content/uploads/2010/02/wp06-23.pdf.
} 
capital and labor across sectors takes place after the uncertainty is resolved.With this timing, the subscript $t$ signifies that a variable is measurable with respect to the information available up to period $t$, including period $t$ productivity shocks in both sectors.

\section{Equilibrium in the World Economy and the Small Economy}

In this section, we characterize the equilibrium of the world economy and the small economy. We begin with the world economy.

\subsection{Equilibrium in the world economy}

Our assumption that the small economy's population is of zero measure compared with the population of the world economy implies that the world economy behaves as a closed economy and that the prices of the intermediate goods are determined by the world economy's equilibrium alone.

In the absence of uncertainty the world economy will converge to a unique steady state. In the steady state the prices of the intermediate goods, $p_{a}$ and $p_{m}$, the price of the final goods $p^{w}$ and the interest rate in the world economy will be constant across time. We normalize the world price of the final good, $p^{w}$, to be equal to 1.

In our analysis of the equilibrium of the small economy we assume that the world is in the steady state. The world economy's equilibrium determines the intermediate-goods prices, $p_{a}$ and $p_{m}$, prevailing universally in both the world and the small economies. Therefore, in our analysis of the small economy, the prices of intermediate goods are given and constant across time. Also, since we are concentrating on the equilibrium of the small economy only, we drop the superscript $s$ from all variables. We distinguish world variables with a superscript $w$ whenever necessary.

\subsection{Decision problems in the small economy}

In the small economy, the representative household maximizes its lifetime expected utility subject to the period budget constraint, and taking prices of labor, $w_{t}$, capital, $r_{t}$, and final good, $p_{t}$, as given. Thus, the representative household's 
decision problem is to choose the consumption, $c_{t}$, investment, $x_{t}$, and capital, $k_{t}$, to solve:

$$
\begin{aligned}
\max _{\left\{c_{t}, x_{t}, k_{t}\right\}_{t=1}^{\infty}} & E_{1}\left[\sum_{t=1}^{\infty} \beta^{t-1} u\left(c_{t}\right)\right] \\
\text { s.t. } p_{t}\left(c_{t}+x_{t}\right) \leq & w_{t}+r_{t} k_{t-1}, \\
k_{t} & =(1-\delta) k_{t-1}+x_{t},
\end{aligned}
$$

given the initial level of per capita capital $k_{0}$.

Note that markets are incomplete; there are no contingent assets available to the households to insure themselves against risk. Moreover, the budget constraints do not allow for borrowing or lending. The lack of borrowing or lending is a reflection of the period-by-period balanced trade constraint described earlier.

The above maximization problem results in the following dynamic optimality conditions:

$$
\begin{aligned}
u^{\prime}\left(c_{t}\right) & =\beta E_{t}\left[u^{\prime}\left(c_{t+1}\right)\left(1-\delta+\frac{r_{t+1}}{p_{t+1}}\right)\right], \\
c_{t}+k_{t} & =\frac{w_{t}}{p_{t}}+\frac{r_{t}}{p_{t}} k_{t-1}+(1-\delta) k_{t-1} .
\end{aligned}
$$

These equations determine the dynamics of per capita capital and per capita wealth in this model.

On the production side, there are two kinds of firms in the economy: finalgood firms and intermediate-goods firms. We assume that each firm operates in a perfectly competitive environment. The representative final-good firm takes the prices of the intermediate goods as given and solves the following problem:

$$
\begin{aligned}
& \min _{a_{t}^{d}, m_{t}^{d}} \frac{p_{a}}{p_{t}} a_{t}^{d}+\frac{p_{m}}{p_{t}} m_{t}^{d}, \\
& \text { s.t. } Y_{t} \leq z_{t} H\left(a_{t}^{d}, m_{t}^{d}\right) .
\end{aligned}
$$

As noted earlier, variables with superscript $d$ are the quantities demanded in the economy, while variables without the superscripts are the quantities produced in the economy. The first order conditions for the final-good firm are,

$$
\begin{aligned}
\frac{p_{a}}{p_{t}} & =z_{t} H_{1}\left(a_{t}^{d}, m_{t}^{d}\right), \\
\frac{p_{m}}{p_{t}} & =z_{t} H_{2}\left(a_{t}^{d}, m_{t}^{d}\right) .
\end{aligned}
$$


Given world prices of intermediate goods, these equations determine the relative quantities of intermediate goods demanded in the small economy.

The representative intermediate-goods firm in each economy chooses how to allocate the total capital and labor available in that economy across the two sectors 9 . It takes world prices of intermediate goods and domestic factor prices as given and solves,

$$
\begin{aligned}
\min _{K_{a t}, L_{a t}, K_{m t}, L_{m t}} & \frac{r_{t}}{p_{t}}\left(K_{a t}+K_{m t}\right)+\frac{w_{t}}{p_{t}}\left(L_{a t}+L_{m t}\right) \\
\text { s.t. } a_{t} \leq & F\left(K_{a t}, L_{a t}\right) \\
m_{t} \leq & G\left(K_{m t}, L_{m t}\right) .
\end{aligned}
$$

Let us define the intensive form of the intermediate production functions as:

$$
\begin{aligned}
f(k) & =F\left(\frac{K}{L}, 1\right), \\
g(k) & =G\left(\frac{K}{L}, 1\right) .
\end{aligned}
$$

The following equations give the first order conditions in terms of the intensive production functions,

$$
\begin{aligned}
p_{a} f^{\prime}\left(k_{a t}\right) & \leq \frac{r_{t}}{p_{t}}, \\
p_{a}\left[f\left(k_{a t}\right)-f^{\prime}\left(k_{a t}\right) k_{a t}\right] & \leq \frac{w_{t}}{p_{t}}, \\
p_{m} g^{\prime}\left(k_{m t}\right) & \leq \frac{r_{t}}{p_{t}}, \\
p_{m}\left[g\left(k_{m t}\right)-g^{\prime}\left(k_{m t}\right) k_{m t}\right] & \leq \frac{w_{t}}{p_{t}} .
\end{aligned}
$$

Inequalities 3.12 and 3.13 hold with equality whenever sector $a$ is operated with positive inputs, while inequalities 3.14 and 3.15 hold with equality whenever sector $m$ is operated with positive inputs.

\footnotetext{
${ }^{9} \mathrm{We}$ could have had two different intermediate firms, one producing good a while the other producing good $\mathrm{m}$, but the results would have been the same. Since the objective is to find the allocation of capital between the two sectors, we chose to model a representative firm for simplicity and brevity.
} 
Thus, it is the intermediate goods firm that decides whether to produce both intermediate goods in positive quantities, or, in other words, whether the country will diversify. Their first-order conditions can be used to define the boundaries of the "cone of diversification," $k_{a t}^{b}$ and $k_{m t}^{b}$. Whenever the aggregate capital-labor ratio of a small economy belongs to the interior of this cone, $k_{t} \in\left(k_{a t}^{b}, k_{m t}^{b}\right)$, it is profitable to produce both intermediate goods in the small economy. The boundaries $k_{a t}^{b}$ and $k_{m t}^{b}$ are defined as a solution to the following equations:

$$
\begin{aligned}
p_{a} f^{\prime}\left(k_{a t}^{b}\right) & =p_{m} g^{\prime}\left(k_{m t}^{b}\right), \\
p_{a}\left[f\left(k_{a t}^{b}\right)-f^{\prime}\left(k_{a t}^{b}\right) k_{a t}^{b}\right] & =p_{m}\left[g\left(k_{m t}^{b}\right)-g^{\prime}\left(k_{m t}^{b}\right) k_{m t}^{b}\right] .
\end{aligned}
$$

Equations 3.16 and 3.17 are the optimality conditions that equate marginal products of capital and labor in two intermediate sectors. They must be satisfied whenever both intermediate sectors are operated; i.e., when the economy's aggregate capital-labor ratio is within the cone of diversification. In this case, the optimal capital-labor ratios in intermediate sectors $a$ and $m$ are $k_{a t}=k_{a t}^{b}$ and $k_{m t}=k_{m t}^{b}$, respectively. This allows us to dispense with the superscript $b: k_{a t}$ and $k_{m t}$ signify both the boundaries of the cone of diversification and the optimal capital-labor ratios in the two sectors of economies within the cone.

A crucial point is that $k_{a t}$ and $k_{m t}$ are independent of the domestic capitallabor ratio $k_{t-1}$. The allocation of capital and labor between two intermediate sectors, however, depends on the domestic capital-labor ratio. Countries that have a higher capital-labor ratio devote a larger fraction of capital and labor to the capital-intensive sector $m$.

Finally, in any equilibrium the following market-clearing conditions must be satisfied:

$$
\begin{aligned}
a_{t} & =F\left(K_{a t}, L_{a t}\right), \\
m_{t} & =G\left(K_{m t}, L_{m t}\right), \\
C_{t}+X_{t} & =z_{t} H\left(a_{t}^{d}, m_{t}^{d}\right), \\
C_{t} & =c_{t} L, \\
X_{t} & =x_{t} L, \\
K_{a t}+K_{m t} & =K_{t-1}, \\
L_{a t}+L_{m t} & =L .
\end{aligned}
$$

The market clearing conditions are standard. Observe that, in the marketclearing condition for capital, equation 3.23, aggregate capital is determined a 
period earlier than when it is allocated between the two intermediate sectors for production, a consequence of the aforementioned timing assumptions.

\subsection{Equilibrium in the small economy without uncertainty}

Before we discuss convergence in a stochastic environment, let us first understand why there are multiple steady-state equilibria, non-convergence, and specialization in the economies without uncertainty. Suppose a small economy faces no uncertainty and has $z_{t}=z^{w}=1$ for all $t$ and in all states of nature. In this case the price of the final good in the small economy is always equal to the final goods price in the world economy $p_{t}=p^{w}=1$.

There are two possible scenarios for the small economy: it may start with a capital-labor ratio either within the diversification cone or outside of it. First, suppose that the initial capital in the small economy, $k_{0}$, is within the diversification cone; i.e., $k_{0} \in\left[k_{a}, k_{m}\right]$. Then, since $k_{a t}=k_{a}^{w}$, we have

$$
r_{t}=p_{a} f^{\prime}\left(k_{a t}\right)=p_{a} f^{\prime}\left(k_{a}^{w}\right)=r^{w} .
$$

Similarly, $w_{t}=w^{w}$.

Thus, factor-price equalization occurs across the economies. The fact that real interest rates are equal across countries means that there is no incentive for cross-economy borrowing and lending, and period-by-period balanced trade is not constraining the equilibrium. Further, identical rates of return in both economies mean that the incentives to accumulate capital are the same in both economies, and, since the world economy is in the steady state, the small economy will also be in the steady state at the initial capital-labor ratio. Thus, any capital-labor ratio within the diversification cone can be sustained as a steady state.

Next, consider the case where the small economy starts at a capital-labor ratio that is outside of the diversification cone. In particular, suppose that the economy starts with a very low capital-labor ratio, $k_{0}<k_{a}$. In this case, as long as $k_{t-1}<$ $k_{a}$, it is optimal to produce only the less capital-intensive good, and we have

$$
r_{t}=p_{a} f^{\prime}\left(k_{t-1}\right)>r_{t}^{w}=p_{a} f^{\prime}\left(k_{a}\right) .
$$

The real interest rate in the small economy will be larger than the world real interest rate, and the small economy will accumulate capital until it reaches (asymptotically) the lower boundary of the diversification cone. Once it reaches the boundary, i.e., when $k_{t-1}=k_{a}$, again there is factor-price equalization, and the economy will stop accumulating capital. Hence, the small economy will be 
at a steady state at the lower boundary of the diversification cone and will produce only the less capital-intensive good $a$. The case where the economy starts at $k_{0}>k_{m}$ is symmetric.

The crucial difference between a one-sector closed economy and an open economy with two tradable sectors is that in the former the interest rate is a function of its own capital in the economy, while in the open economy, within the diversification cone, it is independent of the small economy's aggregate capital. As a result, even though there is a unique capital-labor ratio for a given interest rate in a closed economy, several aggregate capital-labor ratios are sustainable for a given interest rate in the case of an open economy; all that differs is the share of capital and labor resources devoted to the two intermediate goods. This is crucial in delivering multiple steady states in a deterministic dynamic Heckscher-Ohlin model.

\subsection{Equilibrium in the stochastic small economy}

In this section we analyze the model with uncertainty, i.e., when $z_{t}$ is stochastic and state the two main results about convergence and diversification.

Define the per capita income of the small economy as $y_{t}=\frac{w_{t}}{p_{t}}+\frac{r_{t}}{p_{t}} k_{t-1}+$ $(1-\delta) k_{t-1}$. It is a function of the small economy's capital-labor ratio, $k_{t-1}$, and productivity shock $z_{t}: y_{t}=y\left(k_{t-1}, z_{t}\right)$. The representative household's problem can be restated as:

$$
\begin{aligned}
\max _{\left\{c_{t}, k_{t}\right\}_{t=1}^{\infty}} & E_{1} \sum_{t=1}^{\infty} \beta^{t-1} u\left(c_{t}\right), \\
\text { s.t. } & c_{t}+k_{t} \leq y\left(k_{t-1}, z_{t}\right) \\
& y\left(k_{0}, z_{1}\right) \text { is given. }
\end{aligned}
$$

This set-up of the household's problem makes it clear that, from the household's perspective, the problem is essentially the same as that faced by an agent in a one-sector stochastic growth model with i.i.d. shocks. Given this set-up, the optimal consumption and investment policy functions in any period $t$ will be functions of current income, $y_{t}$, only. For our main result on convergence, we need to establish the continuity and monotonicity properties of our policy functions. As a first step we establish the continuity and monotonicity properties of the income function, which is achieved in Lemma 1. 


\section{Lemma 1. Properties of the small economy's income function, $y \cdot \sqrt{10}$}

- $y$ is continuous in $k$, and $z$. It is strictly increasing in $k$ and $z$.

- For every $z \in Z$, the function $y(\cdot, z): R_{+} \rightarrow R_{+}$is concave, and continuously differentiable. For every $k>0$, the derivative $\frac{\partial y(k, \cdot)}{\partial k}$ is continuous in $z$.

- There exists the maximum sustainable level of capital, $\bar{k}$, such that $y(k, z)<$ $\bar{k}$ for all $k>\bar{k}$ and for all $z \in Z$.

Let $X=[0, \bar{k}]$. Define the value function $v\left(k_{0}, z\right)$ as the maximum lifetime expected utility attained in the problem 3.26 . It is a standard result that the value function is unique, bounded, strictly concave, continuously differentiable in $k$ (for $k>0$ ), and solves the following Bellman equation,

$$
v(k, z)=\max _{k^{\prime} \in[0, y(k, z)]}\left[u\left(y(k, z)-k^{\prime}\right)+\beta \int v\left(k^{\prime}, z^{\prime}\right) \eta\left(d z^{\prime}\right)\right] .
$$

Further, for each $z \in Z, v(\cdot, z): X \rightarrow R_{+}$is strictly increasing and $v(0, z)=$ 0 .

The investment policy function $h(k, z)$ is defined so that

$$
v(k, z)=u(y(k, z)-h(k, z))+\beta \int v\left(h(k, z), z^{\prime}\right) \eta\left(d z^{\prime}\right) .
$$

In the following proposition we establish the existence, and the continuity and monotonicity properties of both, the investment policy function $h(k, z)$ and the consumption policy function $c(k, z)$.

Proposition 1. Existence, continuity, and monotonicity of the policy functions.

- There exist unique consumption and investment policy functions: $c_{t}=c\left(k_{t-1}, z_{t}\right)$ and $k_{t}=h\left(k_{t-1}, z_{t}\right)$. Both functions are continuous with respect to $k_{t}$, and $z_{t}$, and measurable with respect to the Borel subsets of $Z$.

\footnotetext{
${ }^{10}$ The income function is a smooth envelope of the two intermediate production functions. So it is easy to show that it satisfies all the properties listed in this Lemma. The proof is included in an earlier version of the paper available online at http://www.bankofcanada.ca/wpcontent/uploads/2010/02/wp06-23.pdf.
} 
- Functions $c\left(k_{t-1}, z_{t}\right)$ and $h\left(k_{t-1}, z_{t}\right)$ are strictly increasing in $k_{t-1}$, and $z_{t}$. Also, $c(0, z)=0$ and $h(0, z)=0$ for all values of $z$.

Proof: See Appendix.

Next we establish the properties of the fixed points and stability properties of the investment policy function. We start with fixed points of the function. For any realization $z$, we define $k_{z}$ to be a fixed point for the investment policy function $h(k, z)$; i.e., $k_{z}$ is such that $k_{z}=h\left(k_{z}, z\right)$. We can also define the maximum and minimum positive fixed points for any given realization, $z$, as follows:

$$
\begin{aligned}
k_{z}^{\max } & =\max \{k>0 \mid h(k, z)=k\}, \\
k_{z}^{\min } & =\min \{k>0 \mid h(k, z)=k\},
\end{aligned}
$$

whenever they exist.

In the next proposition we show that the investment policy function possesses certain stability properties.

Proposition 2. Fixed points and stability properties of the investment policy function.

- The fixed point $k_{\underline{z}}^{\max }$ exists and for all $k>k_{\underline{z}}^{\max }, h(k, \underline{z})<k$.

- The fixed point $k_{\bar{z}}^{\min }>0$ exists and for all $k<k_{\bar{z}}^{\min }, h(k, \bar{z})>k$.

- The function $h(k, z)$ has a stable configuration; i.e., $k_{\underline{z}}^{\max }<k_{\bar{z}}^{\min }$.

Proof: See Appendix.

Given that we have assumed the shocks to be i.i.d., the policy function $h(k, z)$ defines a Markov process on the set of capital-labor ratios, $X$. Let $\mathcal{B}$ be the Borel sigma field generated by $X$. For all $B \subset \mathcal{B}$, let $P\left(k_{t-1}, B\right)=\operatorname{Pr}\left(k_{t} \in B\right)$ be the transition probability function of the capital-labor ratio process in the small economy. Let $P^{t}(B)=\operatorname{Pr}\left(k_{t} \in B\right)$ be the probability measure for the small economy's capital-labor ratio in period $t$ defined on Borel subsets $B$ of $X$; it is generated by the transition probability function as

$$
P^{t}(B)=\int_{X} P(k, B) P^{t-1}(d k),
$$

starting from some initial distribution, $P_{0}$, defined on $(X, \mathcal{B})$. The invariant distribution over $X$, then, is any probability measure $\mu$, such that

$$
\mu(B)=\int_{X} P(k, B) \mu(d k) .
$$


The economy is generally assumed to start from a given value of the capital, which means that $P^{0}$ is a degenerate distribution concentrated on some positive value of the capital-labor ratio. Our objective is to prove that, no matter which positive value of capital we start from, the $\operatorname{limit}_{t \rightarrow \infty} P^{t}$ is the unique invariant distribution. More precisely, let $\delta_{k_{0}}$ be a degenerate distribution concentrated on $k_{0}$. Let $P^{0}\left(k_{0}, B\right)=\delta_{k_{0}}, \quad P^{1}\left(k_{0}, B\right)=P\left(k_{0}, B\right)$, and $P^{t}\left(k_{0}, B\right)=$ $\int_{X} P(k, B) P^{t-1}\left(k_{0}, d k\right)$ for any set $B \subset \mathcal{B}$. We need to show that $\lim _{t \rightarrow \infty} P^{t}\left(k_{0}, B\right)=$ $\mu(B)$ for all positive $k_{0}$ and any Borel subset $B$ in $\mathcal{B}$.

\section{Theorem 1. Convergence.}

There exists the unique invariant probability measure $\mu$ on $(X, \mathcal{B})$, such that $\lim _{t \rightarrow \infty} P^{t}\left(k_{0}, B\right)=\mu(B)$ for all $k_{0}>0$. The full support of $\mu$ is the unique non-degenerate compact interval on $\mathcal{R}_{++}$given by $\left[k_{\underline{z}}^{\max }, k_{\bar{z}}^{\min }\right]$.

Proof: See Appendix.

The above theorem states that, no matter where different small economies start, in the long-run per capita capital converges to the same invariant distribution with its support being the interval $\left[k_{z}^{\max }, k_{\bar{z}}^{\min }\right]$. The lower boundary of the interval $k_{\underline{z}}^{\max }$ is the maximum fixed point of the policy function for the worst shock, while the upper boundary is the minimum fixed point of the policy function for the best shock. As shown in Proposition 2, this interval is non-degenerate, and, since $k_{\underline{z}}^{\max }>0$, bounded away from zero.

The fact that the invariant distribution is unique is illustrated in Figure 1, which shows two policy functions, one for the worst shock, $\underline{z}$, and the other for the best shock, $\bar{z}$,. The capital-labor ratio in the shaded region, marked as the invariant set, is the full support for the invariant distribution. Any economy that has capitallabor ratio in that region will always remain there-the worst that can happen is that the economy faces the worst shock each period, and then its capital-labor ratio will converge to the lower boundary. In the best possible case, when the country faces the best shock every period, the capital-labor ratio goes to the upper boundary. Since the policy function, $h(k, z)$, is continuous and non-decreasing in $z$, and the shocks come from a full compact support, every non-degenerate interval of capital-labor ratios within the invariant set is attainable with positive probability. Now, consider the case when the initial capital-labor ratio is below the minimum point of the interval $\left[k_{z}^{\max }, k_{\bar{z}}^{\min }\right]$. A sequence of good shocks, which occurs with positive probability, will eventually bring the ratio inside the interval. The case when the capital-labor ratio is above the interval is symmetric. Thus, $\left[k_{\underline{z}}^{\max }, k_{\bar{z}}^{\min }\right]$ 
will be the unique, globally stable, full support for the invariant distribution. Note that even a small amount of uncertainty is sufficient for our result.

Thus, in the long run, there will be convergence in the per capita capital stock and, hence, convergence in the per capita income levels across countries, no matter where different small economies start from.

Our next theorem helps us to answer the question whether a small economy will diversify. To make this determination, we need to find out whether there is any intersection between the support of the invariant set and the diversification cone. Recall that $k_{a}$ and $k_{m}$ are the capital-labor ratios in sectors $a$ and $m$ in the small economy, whenever this economy produces positive amounts of both intermediate goods. They are independent of the small economy's capital. Theorem 2 relates $k_{a}$ and $k_{m}$ with $k_{\underline{z}}^{\max }$ and $k_{\bar{z}}^{\min }$,the boundaries of the invariant set.

\section{Theorem 2. Diversification.}

$\left[k_{a}, k_{m}\right] \subset\left[k_{\underline{z}}^{\max }, k_{\bar{z}}^{\min }\right]$.

\section{Proof: See Appendix.}

This theorem proves that the entire diversification cone is a proper subset of the invariant set. In the invariant distribution, therefore, a small economy may visit the entire diversification cone and also some areas outside of it.

Note that here we are focussing on the convergence of income levels across small open economies and not between the small economy and the world. However, the theorem on diversification helps us to relate the invariant set of a small economy to the steady state level of capital in the world economy. Since the world's capital-labor ratio lies within the diversification cone, and the invariant set contains the diversification cone, the world capital-labor ratio is contained in the invariant set for the small economy.

The above theorems provide insight to the relation of factor prices across the countries. First notice that in this stochastic model the real factor prices $\frac{w_{t}}{p_{t}}$ and $\frac{r_{t}}{p_{t}}$ depend on the realization of productivity shock in period $t$. Thus, in general, there is no factor price equalization across economies (either across small open economies or between a small open economy and the world economy). Factor prices are equal across two small open economies only in the special case when both the countries are within the diversification cone and they face the same shocks. However, even if two economies have their factor prices equalized in any given period, there is no guarantee that factor prices will be equal in the future. First, the future realized productivity shocks might be different across these two economies, and second, one or both economies might find themselves outside the 
diversification cone. This is due to Theorem 2, From that theorem we know that a small economy will definitely be outside the diversification cones in some periods. In those periods factor prices in this economy will depend on its own capital-labor ratio, and will not be equalized with factor prices in another economy, which has the same productivity shock, but different capital-labor ratio.

\section{Simulation of the Small Economy}

So far we have shown that with uncertainty and balanced trade there will be convergence, but our results are silent about the path or the speed of convergence. We simulate our model using the utility function $u(c)=\frac{c^{(1-\nu)}}{1-\nu}$ and Cobb-Douglas production functions to make that determination.

The parameter values used in this exercise is given below:

\begin{tabular}{cccccc}
\hline$\alpha$ & $\gamma$ & $\mu$ & $\delta$ & $\beta$ & $\nu$ \\
0.3 & 0.4 & 0.2 & 0.08 & 0.95 & 1.5 \\
\hline
\end{tabular}

Where, $\alpha$ is the share of capital income in sector $a, \gamma$ is the share of capital income in sector $m, \mu$ is the share of good $a$ in the final good.

We first simulate the economy when there is no uncertainty. Figure 2 plots the paths for capital in a deterministic Heckscher-Ohlin model: a country that starts with capital-labor ratio less than $k_{a}$ grows until it reaches the lower boundary of the diversification cone, and then its capital-labor ratio is fixed at that level. The case with countries that start with a capital-labor ratio greater than $k_{m}$ is symmetric.

Next we simulate the small economy with uncertainty. We assume that there are two possible productivity states, high and low, with equal probability ${ }^{11}$ and then simulate our model for different magnitudes of the shocks.

We find that the bigger are the possible shocks in the small economy, the quicker is the convergence. This is illustrated in the Figure 3, where we report two cases with deviation of productivity from the mean being: (i) 5 percent, and (ii) 10 percent.

The fact that the speed of convergence increases with the magnitude of shocks relates our convergence result with that of non-convergence in the deterministic version. The finding suggests that, for small degrees of uncertainty it will

\footnotetext{
${ }^{11}$ Simulations with continuous state space give similar results.
} 
take an extremely long time for economies to converge. In the limit, when uncertainty is driven to zero, convergence disappears altogether. Thus, the deterministic Heckscher-Ohlin model is a special case of the stochastic model.

Our simulation is useful in another dimension as well: it allows us to visualize the actual shape of the investment policy function. A plot of the policy function in Figure 4 reveals the effect of uncertainty and market incompleteness in our model. The policy functions for high and low shocks shift apart from each other. This is a consequence of the representative agent's motives to self-insure by accumulating more (less) capital when the income is higher (lower) than expected due to a high (low) productivity shock.

Further, with uncertainty (i.i.d. shocks) the policy function tilts-it is above the 45 degree line for low values of the capital-labor ratios. This is in contrast to the deterministic case, where the investment policy function coincides with the 45-degree line everywhere within the diversification cone, making every point a fixed point and a steady state.

We also use simulations to look at the dynamics when the stochastic process is not i.i.d. In this paper we have proved our results using the assumption that the shocks are i.i.d., so naturally the question remains about the validity of our results when the shocks are Markovian. While proving the results theoretically for such a stochastic process is likely to be involved and difficult, we can easily simulate the capital path for such an economy. We simulate the capital paths for a symmetric Markov chain defined over two possible productivity states, high and low ${ }^{12}$. We find that even with correlated shocks the capital (and, hence income) in a small economy converges to an invariant distribution irrespective of the initial capital. We also find that the diversification cone is contained within the invariant set, similar to the i.i.d. case. In Figure 5 we plot the mean capital paths for an initially poor and an initially rich country for i.i.d. shocks as well as for a twostate Markov chain in which the same state repeats with probability of 0.6 and 0.9 . When compared to the i.i.d. case the convergence is faster when shocks are persistent. With persistense, if a bad (good) productivity shock hits the economy, it is likely to be followed by more bad (good) shocks. This strengthens the representative agent's self insurance motive. Further, with persistent shocks, when a good shock hits the economy, it is likely to be followed by a series of good shocks. This increases the chances that an initially poor economy quickly accumulates more capital and moves to the upper boundary of the invariant set. Similarly, a

\footnotetext{
${ }^{12}$ Simulations with Markov chains defined over 3, 4 or 5 states, with transition probabilities approximating $\mathrm{AR}(1)$ processes give similar results.
} 
bad productivity shocks is likely to be followed by a series of bad shock, which would quickly pin an initially rich economy against the lower boundary of the invariant set. Thus, higher persistence induces faster convergence across various economies by increasing the degree of mobility across income levels.

\section{Worldwide Shock: No Convergence}

To understand the role of country-specific uncertainty, in this section we present a model in which there are world-wide shocks, i.e., all countries are affected by same shocks. We show analytically that, in this particular example, countries do not converge and may permanently specialize in producing only one tradable good.

We assume that both the world and the small economy face identical shocks: i.e., $z_{t}^{w}=z_{t}^{s}$ for all $t$. We use specific functional forms for the utility and the production functions. The utility function is logarithmic, $u(c)=\ln (c)^{13}$. The individual production functions are given by,

- final-good technology: $z H(a, m)=z a^{\mu} m^{1-\mu}$,

- intermediate-good $a$ technology: $F(K, L)=K^{\alpha} L^{1-\alpha}$; and intermediategood $m$ technology: $G(K, L)=K^{\gamma} L^{1-\gamma}$,

where $1>\gamma>\alpha>0$. Further, we assume full depreciation (i.e., $\delta=1$ ). Since in this example we provide the dynamics of both the world and the small economy, we distinguish them using superscript $w$ for the world economy and $s$ for the small economy.

The optimal capital-labor ratio in the world economy evolves according to the following law of motion:

$$
k_{t}^{w}=Q z_{t}\left(k_{t-1}^{w}\right)^{q}
$$

where $Q$ is a positive constant, and $q=\alpha \mu+\gamma(1-\mu)$. Since $q<1$, the world capital-labor ratio converges to a unique invariant distribution. We assume that the world economy's capital-labor ratio is drawn from this invariant distribution. The

\footnotetext{
${ }^{13}$ In proving our theorems on convergence and diversification in the previous sections we assumed utility is bounded below, but here we deviate from that assumption. The assumption on utility was to ensure that the optimal capital path will be bounded away from zero, here the use of Cobb-Douglas utility function precludes that even with unbounded utility function.
} 
above law of motion for the world capital-labor ratio determines a Markov process for intermediate-good prices $p_{a t}, p_{m t}$. Note that the prices of the intermediate goods are no longer constant across time.

It can be shown that the boundaries of the diversification cone are constant fractions of the aggregate capital: $k_{a t}^{w}=\phi_{a} k_{t-1}^{w}$ and $k_{m t}^{w}=\phi_{m} k_{t-1}^{w}$, where $\phi_{a} \in$ $(0,1)$, while $\phi_{m}>1$.

Suppose that, at the beginning of period $t$, the small economy's capital-labor ratio is $k_{t-1}^{s}>0$. Let $\tau_{t-1}=\frac{k_{t-1}^{s}}{k_{t-1}^{w}}$ be the capital-labor ratio in the small economy relative to that in the world economy. Then, it can be easily shown, that

- if $\tau_{t-1}<\phi_{a}$, then the small economy will produce only good $a$ in period $t$ and $\tau_{t}=\frac{k_{t}^{s}}{k_{t}^{w}}=\tau_{t-1}\left(\frac{\tau_{t-1}}{\phi_{a}}\right)^{\alpha-1}>\tau_{t-1}$.

- if $\tau_{t-1} \in\left[\phi_{a}, \phi_{m}\right]$, then the small economy will produce both goods, $a$ and $m$, in period $t$ and $\tau_{t}=\tau_{t-1}$.

- if $\tau_{t}>\phi_{m}$, then the small economy will produce only good $m$ in period $t$ and $\tau_{t}=\tau_{t-1}\left(\frac{\tau_{t-1}}{\phi_{m}}\right)^{\gamma-1}<\tau_{t-1}$.

Therefore, whenever the small economy has an aggregate capital-labor ratio outside the diversification cone $\left[k_{a t}, k_{m t}\right]$, it moves towards the diversification cone (and the world capital-labor ratio). If, on the other hand, the small economy starts within the diversification cone, it will maintain a constant ratio between the domestic aggregate capital-labor ratio, $k_{t}^{s}$, and the world aggregate capital-labor ratio, $k_{t}^{w}$. Thus, if two small economies start within the diversification cone, but with different capital-labor ratios relative to that of the world economy, they will maintain those relative positions. Hence, there is no convergence in income or consumption. Also, if any small economy starts with capital-labor ratios outside the diversification cone, it will always specialize in the production of only one tradable commodity.

The difference between this example and the stochastic version considered earlier is that in this example both the small and the world economies face identical shocks; i.e., $z_{t}^{w}=z_{t}^{s}$ for all $t$. Agents of both economies would still try to self-insure by accumulating more or less capital in response to these income shocks. Global shocks, however, would prevent countries from changing their relative wealth positions. 
While this is clearly a very special example, it does show that without countryspecific shocks, income convergence and production diversification may not occur.

On a more technical level, the difference between this section and the previous sections is the nature of shocks the small economy faces. Since the world is now subject to shocks, intermediate-good prices, $p_{a t}$ and $p_{m t}$, follow a Markov process. As a result, the shocks that the small economy faces are autocorrelated. This is in contrast to the shocks being i.i.d. in the previous sections. Thus, the example illustrates the possibility of having a multiplicity of invariant distributions of capital with suitably correlated shocks.

\section{Conclusion}

In this paper we build a dynamic Heckscher-Ohlin model for a small economy with uncertainty and study the equilibrium properties of that model. We show that, in an uncertain world, when markets are incomplete, different small economies will have the same average long-run income irrespective of where they start from. Our results, thus, extend the predictions of income convergence, standard in onesector neoclassical growth models, to a multi-sector open economy in the dynamic Heckscher-Ohlin environment.

We also show that, there will certainly be some periods in which a small open economy diversifies, even if it starts with a very low capital stock. In fact a small economy with two tradable sectors will visit the entire cone of diversification (and some areas outside the cone). Both the convergence and the diversification results represent a departure from the deterministic version of the dynamic HeckscherOhlin model.

The paper also highlights the role of the period-by-period trade balance constraint, a standard feature of deterministic models, in a model with country-specific shocks. Since this constraint precludes risk sharing using borrowing and lending, countries try to self-insure through their savings decision.

The results of the deterministic version and the stochastic version may seem to fit into two extremes, but our simulation results give a sense of continuity between the two cases: the smaller the shocks, the slower is the convergence, and in the limit, with no uncertainty, there is no convergence. Convergence also occurs when shocks are persistent. Higher persistence results in faster convergence. Thus, this paper suggests that the path of development will depend on the nature and extent of uncertainty, though eventually countries will converge in terms of 
income levels.

\section{Acknowledgements}

A version of this paper was earlier circulated with the title "Convergence in a Stochastic Dynamic Heckscher-Ohlin Model." We are extremely grateful to Michele Boldrin for his guidance and constant support. We thank V.V. Chari, Larry Jones, and Tim Kehoe and an anonymous referee for valuable suggestions. We also thank Soma Dey, Urvi Neelakantan, Han Ozsoylev, and Shino Takayama for useful discussions. We also thank participants in various seminars and conferences for helpful comments. Partha Chatterjee acknowledges financial support from NUS through RP grant R-313-000-078-112. 


\section{Appendix}

\section{A Proof of Proposition 1}

The assumptions on the utility function $u(c)$ place this problem into the domain of "Bounded Return Problems," as defined in section 9.2 of Stokey, Lucas and Prescott (1989). It is straightforward to verify that their assumptions 9.4 to 9.12 are satisfied by our model. The results of the first part of Proposition 1 then follow from theorems 9.6, 9.7, 9.8, and 9.10 in Stokey, Lucas and Prescott (1989).

$c(0, z)=0$ and $h(0, z)=0$ is obvious. It is easy to show that both policy functions are strictly increasing, continuous functions of $y{ }^{14}$ Therefore, these policy functions inherit all the continuity and monotonicity properties of $y$.

\section{B Proof of Proposition 2}

The proof of the main theorem in Chatterjee and Shukayev (2008) can be applied to show that, the policy function $h(k, \underline{z})$ for the worst possible shock has at least one positive, and stable fixed point. Once this is established, the first two results of the proposition follow trivially from monotonicity and boundedness of the investment policy function.

To prove the last result, we will show that $k_{\underline{z}}<k_{\bar{z}}$ for any fixed points of $h(k, \underline{z})$ and $h(k, \bar{z})$ correspondingly. To show this we will first prove the following two claims:

Claim 1: For any fixed point $k_{\bar{z}}$ of $h(k, \bar{z})$ we have $1>\beta \int_{Z} y^{\prime}\left(k_{\bar{z}}, z\right) \eta(d z)$.

Proof: From the Euler equation, we have

$$
u^{\prime}\left(c\left(k_{\bar{z}}, \bar{z}\right)\right)=\beta \int_{Z} u^{\prime}\left(c\left(k_{\bar{z}}, z\right)\right) y^{\prime}\left(k_{\bar{z}}, z\right) \eta(d z) .
$$

Since $u^{\prime}\left(c\left(k_{\bar{z}}, z\right)\right) \geq u^{\prime}\left(c\left(k_{\bar{z}}, \bar{z}\right)\right)$, with strict inequality for some $z \in Z$,

$$
\begin{aligned}
u^{\prime}\left(c\left(k_{\bar{z}}, \bar{z}\right)\right) & >\beta u^{\prime}\left(c\left(k_{\bar{z}}, \bar{z}\right)\right) \int_{Z} y^{\prime}\left(k_{\bar{z}}, z\right) \eta(d z) \\
1 & >\beta \int_{Z} y^{\prime}\left(k_{\bar{z}}, z\right) \eta(d z) .
\end{aligned}
$$

Claim 2: For any fixed point $k_{\underline{z}}$ of $h(k, \underline{z})$, we have $1<\beta \int_{Z} y^{\prime}\left(k_{\underline{z}}, z\right) \eta(d z)$. Proof: From the Euler equation, we have

$$
u^{\prime}\left(c\left(k_{\underline{z}}, \underline{z}\right)\right)=\beta \int_{Z} u^{\prime}\left(c\left(k_{\underline{z}}, z\right)\right) y^{\prime}\left(k_{\underline{z}}, z\right) \eta(d z) .
$$

\footnotetext{
${ }^{14}$ For example, see proofs of lemmas 1.1 and 1.2 in Brock and Mirman (1972).
} 
Since $u^{\prime}\left(c\left(k_{\underline{z}}, z\right)\right) \leq u^{\prime}\left(c\left(k_{\underline{z}}, \underline{z}\right)\right)$, with strict inequality for some $z \in Z$,

$$
\begin{aligned}
u^{\prime}\left(c\left(k_{\underline{z}}, \underline{z}\right)\right) & <\beta u^{\prime}\left(c\left(k_{\underline{z}}, \underline{z}\right)\right) \int_{Z} y^{\prime}\left(k_{\underline{z}}, z\right) \eta(d z) \\
1 & <\beta \int_{Z} y^{\prime}\left(k_{\underline{z}}, z\right) \eta(d z) .
\end{aligned}
$$

The above two claims, along with the fact that $y^{\prime}(k, z)$ is decreasing in $k$ for every value of $z$, establish $k_{\underline{z}}<k_{\bar{z}}$.

\section{Proof of Theorem 1}

First we show that the optimal capital sequence $\left\{k_{t}=h\left(k_{t-1}, z_{t}\right)\right\}_{t=1}^{\infty}$ is bounded away from zero. The proof of the main theorem in Chatterjee and Shukayev (2008) can be applied to show that, for any $k_{0}>0$ there exists $\underline{k} \in\left(0, k_{0}\right)$ such that for all $t=$ $1,2,3, \ldots, k_{t} \geq \underline{k}$. Thus, without loss of generality, we can take $X=[\underline{k}, \bar{k}]$.

Now we will prove the theorem by showing that Theorem 2 of Hopenhayn and Prescott (1992) can be applied to our model. We show that, the three assumptions of the Theorem 2 of Hopenhayn and Prescott (1992) are satisfied:

1. the domain set $X$ contains its lower and upper bounds.

- Since $X=[\underline{k}, \hat{k}]$ is a compact set it satisfies this assumption.

2. the transition probability $P(k, B)$ is increasing in $k$ in the sense of first-order stochastic dominance.

- Since $h(k, z)$ is increasing in $k$ for every $z, P(k, B)$ is indeed increasing.

3. Monotone Mixing Condition: there exist some $\tilde{k} \in X$ and an integer $M$ such that $P^{M}(\bar{k},[\underline{k}, \tilde{k}])>0$ and $P^{M}(\underline{k},[\tilde{k}, \bar{k}])>0$.

- Let us define $y^{\prime}=\frac{\partial y}{\partial k}$ for brevity.

Consider the following set $\tilde{K}=\left\{k \in X \mid \beta \int_{Z} y^{\prime}(k, z) \eta(d z)=1\right\}$. Continuity and monotonicity of $y^{\prime}(\cdot, z)$ for every $z$ guarantee that $\tilde{K}$ is non-empty, 
although, in general it may contain more than one point. Let $\tilde{k}$ be any point in $\tilde{K}$.

Let the sequence $\left\{k_{n}\right\}_{n=0}^{\infty}$ be generated as $k_{n}=h\left(k_{n-1}, \underline{z}\right)$ with $k_{0}=\bar{k}$. By the monotonicity of optimal policy rule, $\left\{k_{n}\right\}$ is decreasing, and we know from Proposition 2 that $k_{n} \rightarrow k_{\underline{z}}^{\max }$. For any $\varepsilon>0$, the rectangle $[(\underline{\lambda}, \underline{\theta}),(\underline{\lambda}+$ $\varepsilon, \underline{\theta}+\varepsilon)]$ has a positive measure under $\eta$. This, together with the continuity of $h(k, \cdot)$, implies that the probability of entering into any neighborhood of $k_{\underline{z}}^{\max }$ in a finite number of steps is positive.

From Claim 2 in the proof of Proposition 2, we have $1<\beta \int_{Z} y^{\prime}\left(k_{\underline{z}}^{\max }, z\right) \eta(d z)$. Hence $k_{\underline{z}}^{\max }<\tilde{k}$. An exactly symmetric line of argument establishes that $k_{\bar{z}}^{\min }>\tilde{\tilde{k}}$ and that the sequence $\left\{k_{n}\right\}_{n=0}^{\infty}$ started from $k_{0}=\underline{k}$ enters with positive probability into any neighborhood of $k_{\bar{z}}^{\min }$ in a finite number of steps. The above results prove that there exists some integer $M$ such that $P^{M}(\bar{k},[\underline{k}, \tilde{k}])>0$ and $P^{M}(\underline{k},[\tilde{k}, \bar{k}])>0$.

Thus, all three assumptions of Theorem 2 in Hopenhayn and Prescott (1992) are satisfied, which establishes the desired convergence result.

The full support for this invariant distribution is $\left[k_{\underline{z}}^{\max }, k_{\bar{z}}^{\min }\right]$. To see this fact observe that the sequence $\left\{k_{n}\right\}_{n=0}^{\infty}$ generated as $k_{n}=h\left(k_{n-1}, z\right)$, started from any $k_{0}>k_{\underline{z}}^{\max }$, enters with positive probability into any neighborhood of $k_{\underline{z}}^{\max }$. Similarly, $\left\{k_{n}\right\}_{n=0}^{\infty}$ generated as $k_{n}=h\left(k_{n-1}, z\right)$, started from any $k_{0}<k_{\bar{z}}^{\min }$, enters with positive probability into any neighborhood of $k_{\bar{z}}^{\min }$. It is also clear that, once in $\left[k_{\underline{z}}^{\max }, k_{\bar{z}}^{\min }\right]$, the Markov process $P^{t}\left(k_{0}, \cdot\right)$ cannot leave this set. Thus, $k_{\underline{z}}^{\max }$ and $k_{\bar{z}}^{\min }$ must be the boundaries of the ergodic set. To show that the whole interval $\left[k_{\underline{z}}^{\max }, k_{\bar{z}}^{\min }\right]$ is an ergodic set, choose any open interval $\left(k^{1}, k^{2}\right) \in\left[k_{\underline{z}}^{\max }, k_{\bar{z}}^{\min }\right]$ of a certain length $l>0$, and any point $k_{0} \in\left[k_{\underline{z}}^{\max }, k_{\bar{z}}^{\min }\right]$. Without loss of generality assume that $k_{0}<k^{1}$. Observe that, for any $k \in\left(k_{\underline{z}}^{\max }, k_{\bar{z}}^{\min }\right)$, the image $h(k, Z)$ is a non-degenerate interval $[h(k, \underline{z}), h(k, \bar{z})]$, such that $k$ belongs to the interior of this interval. We can then construct an increasing sequence, $k_{n}=h\left(k_{n-1}, z_{n-1}\right)$, such that $0<\frac{\varepsilon}{2}<\left|k_{n}-k_{n-1}\right|<\varepsilon<\frac{l}{2}$. Clearly, this sequence will enter $\left(k^{1}, k^{2}\right)$ in a finite number of steps, say in $N$ steps. By continuity of $h(\cdot, \cdot)$, this sequence can be constructed with a positive measure of shock histories $z^{N}=\left(z_{0}, z_{1}, \ldots, z_{N}\right) \in Z \times Z \times \ldots \times Z$ ( $N$ times $)$. Obviously, for $k_{0}>k^{2}$, we can construct a decreasing sequence. We have therefore proved that $P^{N}\left(k_{0},\left(k^{1}, k^{2}\right)\right)>0$ for some finite $N$. This establishes irreducibility, and hence the ergodicity of $\left[k_{\underline{z}}^{\max }, k_{\bar{z}}^{\min }\right]$. 


\section{Proof of Theorem 2}

From the first-order conditions

$$
\begin{aligned}
\frac{p_{a}}{p_{t}} & =z_{t} H_{1}\left(a_{t}^{d}, m_{t}^{d}\right) \\
\frac{p_{m}}{p_{t}} & =z_{t} H_{2}\left(a_{t}^{d}, m_{t}^{d}\right)
\end{aligned}
$$

it follows that the equilibrium ratio $\frac{a_{t}^{d}}{m_{t}^{d}}$ is fixed at the value $\frac{a^{d}}{m^{d}}$ implied by

$$
\frac{p_{a}}{p_{m}}=\frac{H_{1}\left(a_{t}^{d}, m_{t}^{d}\right)}{H_{2}\left(a_{t}^{d}, m_{t}^{d}\right)}=\frac{H_{1}\left(\frac{a^{d}}{m^{d}}, 1\right)}{H_{2}\left(\frac{a^{d}}{m^{d}}, 1\right)}
$$

and that the price of the final good $p_{t}$ is proportional to the inverse of $z_{t}$

$$
p_{t}=\frac{p_{a}}{H_{1}\left(\frac{a^{d}}{m^{d}}, 1\right)} \frac{1}{z_{t}} .
$$

The same relation holds for the world economy, where the price of the final good is fixed at

$$
p^{w}=\frac{p_{a}}{H_{1}\left(\frac{a^{d}}{m^{d}}, 1\right)} \frac{1}{z^{w}}=1
$$

since $p^{w}$ is normalized to be 1 . Since the world economy is assumed to be in a steady state, we must have

$$
\beta\left[\frac{p_{a}}{p^{w}} f^{\prime}\left(k_{a}^{w}\right)+1-\delta\right]=\beta\left[z^{w} H_{1}\left(\frac{a^{d}}{m^{d}}, 1\right) f^{\prime}\left(k_{a}^{w}\right)+1-\delta\right]=1 .
$$

We will prove now that for all $k \in\left[k_{a}^{w}, k_{m}^{w}\right]$, where $k$ is the capital-labor ratio of the small economy, the following must be true: $\beta \int_{Z} y^{\prime}(k, z) \eta(d z)=1$. Once that is established the results of the proposition follow from claims 1 and 2 in the proof of the proposition 2 . 
Fix any $k \in\left[k_{a}^{w}, k_{m}^{w}\right]$. Then we have

$$
\begin{aligned}
\beta \int_{Z} y^{\prime}(k, z) \eta(d z) & =\beta \int_{Z}\left[\frac{p_{a}}{p(z)} f^{\prime}\left(k_{a}^{w}\right)+1-\delta\right] \eta(d z) \\
& =\beta\left[p_{a} f^{\prime}\left(k_{a}^{w}\right) \int_{Z} \frac{1}{p(z)} \eta(d z)+1-\delta\right] \\
& =\beta\left[p_{a} f^{\prime}\left(k_{a}^{w}\right) \int_{Z} \frac{H_{1}\left(\frac{a^{d}}{m^{d}}, 1\right) z}{p_{a}} \eta(d z)+1-\delta\right] \\
& =\beta\left[H_{1}\left(\frac{a^{d}}{m^{d}}, 1\right) f^{\prime}\left(k_{a}^{w}\right) \int_{Z} z \eta(d z)+1-\delta\right]= \\
& =\beta\left[z^{w} H_{1}\left(\frac{a^{d}}{m^{d}}, 1\right) f^{\prime}\left(k_{a}^{w}\right)+1-\delta\right]=1 .
\end{aligned}
$$




\section{References}

AiYAGARI, S. R. (1994): "Uninsured Idiosyncratic Risk and Aggregate Saving," Quarterly Journal of Economics, 109(3), 659-684.

Atkeson, A., And P. J. Kehoe (2000): "Paths of Development for Early- and Late-Bloomers in a Dynamic Heckscher-Ohlin Model," Federal Reserve Bank of Minneapolis, Research Department Staff Report, (256).

Bajona, C., And T. Kehoe (2006): "Demographics in Dynamic HeckscherOhlin Models: Overlapping Generations versus Infinitely Lived Consumers," Staff Report 377, Federal Reserve Bank of Minneapolis.

Bajona, C., And T. J. Kehoe (2010): "Trade, Growth, and Convergence in a Dynamic Heckscher-Ohlin Model," Review of Economic Dynamics, 13(3), 487-513.

BARDhan, P. K. (1965): "Equilibrium Growth in the International Economy," Quarterly Journal of Economics, 79, 455-464.

Bond, E. W., K. Trask, And P. WANG (2003): "Factor Accumulation and Trade: Dynamic Comparative Advantage with Endogenous Physical and $\mathrm{Hu}-$ man Capital," International Economic Review, 44, 10411060.

Brock, W. A., And L. J. Mirman (1972): "Optimal Economic Growth And Uncertainty: The Discounted Case," Journal of Economic Theory, 4, 479-513.

Chamberlain, G., And C. Wilson (2000): "Optimal Intertemporal Consumption under Uncertainty," Review of Economic Dynamics, 3, 365-395.

Chatterjee, P., And M. Shukayev (2008): "Note on positive lower bound of capital in the stochastic growth model," Journal of Economic Dynamics and Control, 32(7), 2137-2147.

Chen, Z. (1992): "Long-Run Equilibria in a Dynamic Heckscher-Ohlin Model," Canadian Journal of Economics, XXV(4).

Clarida, R. (1987): “Consumption, Liquidity Constraints and Asset Accumulation in the Presence of Random Income Fluctuations," International Economic Review, 28, 339-351. 
Cunat, A., And M. Maffezzoli (2004a): "Hecksher-Ohlin Business Cycles," Review of Economic Dynamics, 7(3), 555-585.

(2004b): "Neoclassical Growth and Commodity Trade," Review of Economic Dynamics, 7, 707-736.

DATTA, M. (1999): "Optimal accumulation in a small open economy with technological uncertainty," Economic Theory, 13, 207-219.

DeArdorfF, A. (2001): "Rich and Poor Countries in Neoclassical Trade and Growth," The Economic Journal, 111, 277-295.

Findlay, F. (1970): "Factor Proportions and Comparative Advantage in the Long Run," Journal of Political Economy, 78, 27-34.

FISHER, E. O. (1995): "Growth, trade, and international transfers," Journal of International Economics, 39(1-2), 143-158.

Hopenhayn, H. A., and E. C. Prescott (1992): "Stochastic Monotonicity and Stationary Distributions for Dynamic Economies," Econometrica, 60(6), 1387-1406.

Mirman, L., AND I. Zilcha (1975): “On Optimal Growth Under Uncertainty,” Journal of Economic Theory, 11, 329-339.

Muss A, M. (1978): "Dynamic Adjustment in the Heckscher-Ohlin-Samuelson Model," Journal of Political Economy, 86, 775-791.

ONIKI, H., AND H. UZAWA (1965): "Patterns of Trade and Investment in a Dynamics Model of International Trade," Review of Economic Studies, 32, 1538.

Smith, A. (1984): "Capital Theory and Trade Theory," in Handbook of International Economics, ed. by R. W. Jones, and P. B. Kenen, vol. 1, p. 289324. North-Holland.

Stokey, N., R. LuCAs, And E. Prescott (1989): Recursive Methods in Economic Dynamics. Harvard University Press.

TRefler, D. (1993): “International Factor Prices: Leontief Was Right!,” Journal of Political Economy, 101(6), 961-987.

VentuRA, J. (1997): “Growth and Interdependence,” Quarterly Journal of Economics, 112, 57-84. 
Figure 1: Invariant Set

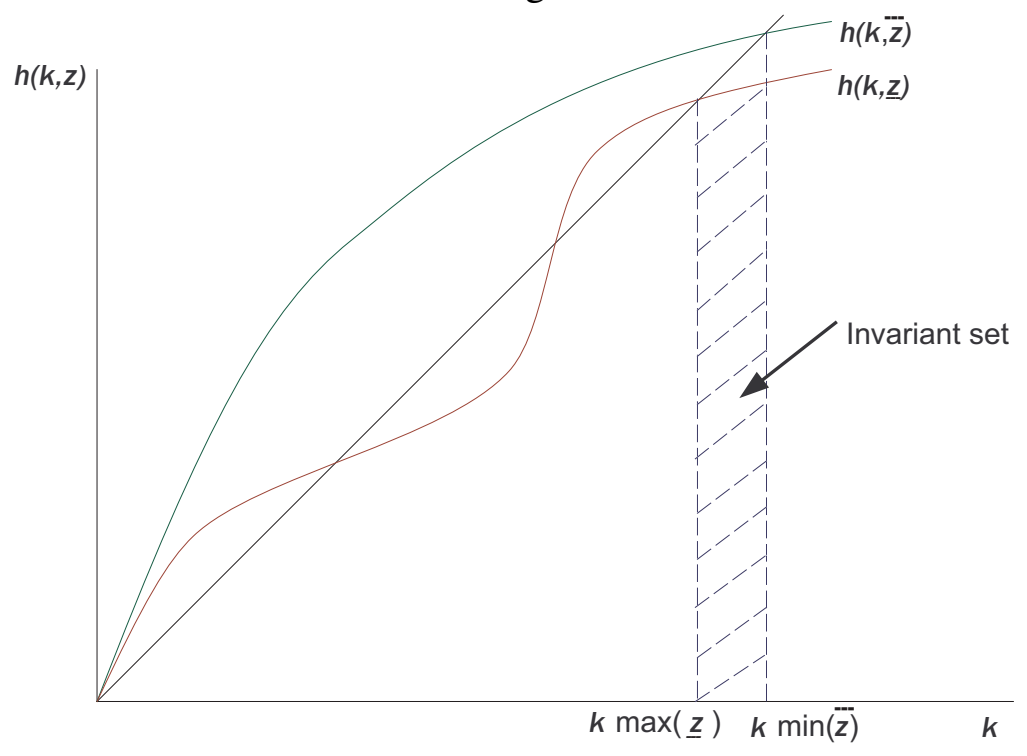


Figure 2: Path of Capital: No Uncertainty

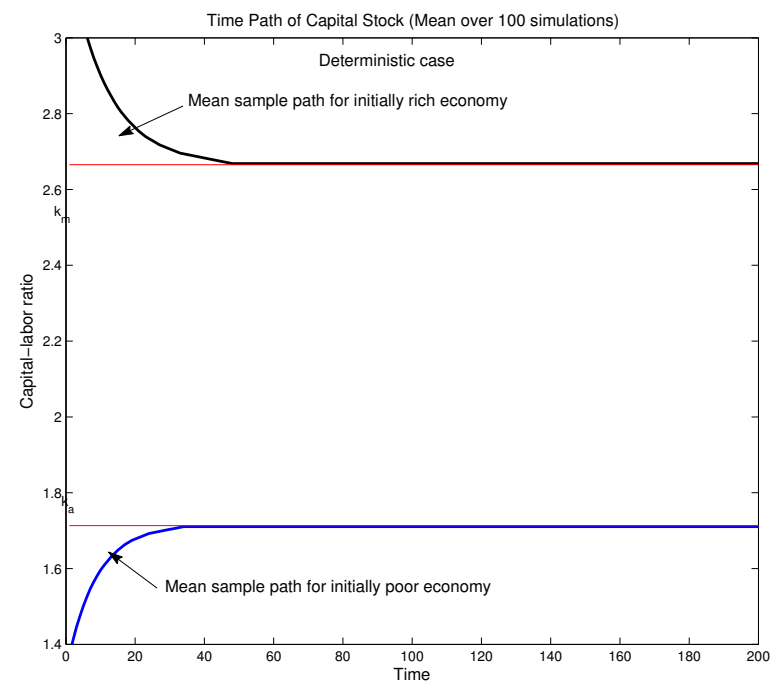

Figure 3: Path of capital with 5\% and 10\% shocks $5 \%$ Shock

$10 \%$ Shock
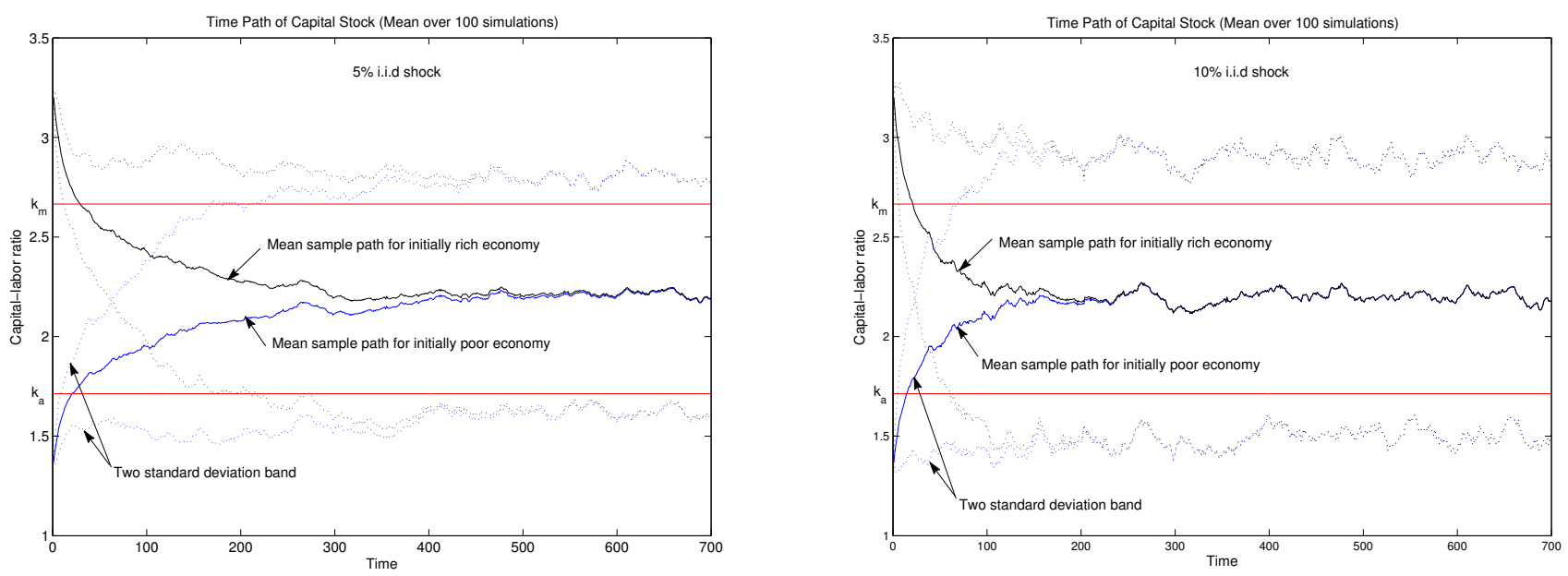
Figure 4: Policy Functions for "High" and "Low" shocks

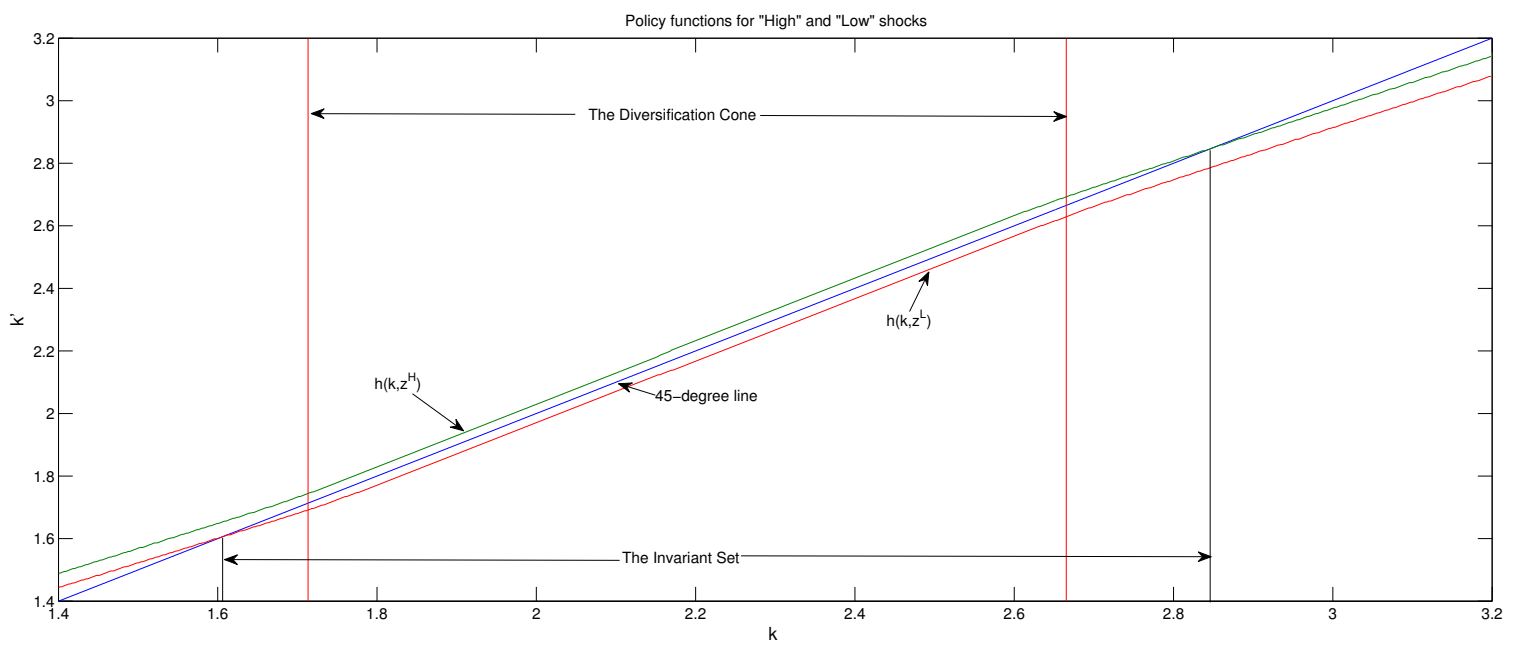

Figure 5: Path of Capital for i.i.d and Markov Processes

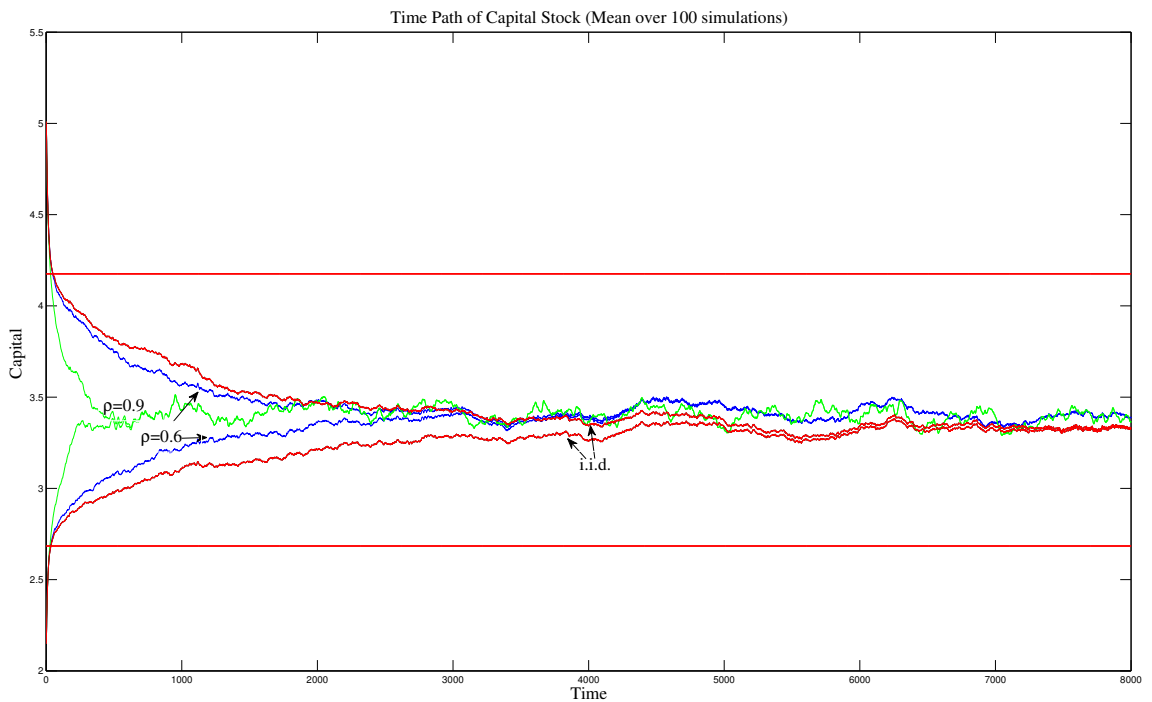

